\section{A brief report on an action learning group exploration of how older people adapt to change in later life}

\author{
Francis C. Biley, ${ }^{1}$ Wendy Hilton, ${ }^{2}$ \\ Jill Phillips, ${ }^{3}$ Michele Board ${ }^{3}$
}

'School of Health and Social Care, Bournemouth University; ${ }^{2}$ Age Concern

Dorchester; ${ }^{3}$ School of Health and Social

Care, Bournemouth University, UK

\section{Abstract}

In collaboration with Age Concern UK, older people were invited to participate in action learning groups to explore how they adapt to change. Themes for discussion were initially identified using a nominal focus method. Discussions identified actual and desired methods of coping with changes in later life. A series of weekly meetings with three cohorts of urban, rural and sheltered accommodation participants with an average age of 81 years revealed that they were concerned with having to cope with and adapt to a wide range of experiences. These included the loss of sharing and reduced sociability, reduced mobility, bereavement, physical changes, having to move house and/or location, having to retire, and having to deal with outside agencies. In order to cope with these experiences, participants engaged in a range of activities that centered on aspects of communication and social networking. Participants talked to each other socially and informally, exchanging information and advice. When able, they also participated in more structured but non-specific social events during which time they also had the opportunity to support each other. Participants suggested that there was a role for statutory and nonstatutory bodies and professions such as mental health and community adult nursing, occupational therapy and social work to provide more formal social networking and information exchange opportunities.

\section{Introduction}

People in later life report sophisticated coping, adaptation and resilience in response to the need to adapt to changes that might occur as a result of, for example, declining functional ability. ${ }^{1,2}$ However, alterations in functional ability, social networks, socioeconomic factors and other demographic changes frequently have a negative impact upon the quality of life reported by those in later life..$^{3-8}$
There is an extensive body of evidence to suggest that, for example, the loss of a spouse may result in lower levels of psychological wellbeing than married individual ${ }^{9,10}$ and that issues related to having a limited social network may impact negatively on mortality rates, particularly for men ${ }^{11}$ Fear of crime and a threat to personal safety may lead to increased isolation and a tendency to stay at home ${ }^{12}$ and loss of mobility ${ }^{13}$ In particular, stopping driving $^{14}$ was a strong predictor of increased depressive symptoms. In an extensive review and meta-analysis of 148 papers, it was report$\mathrm{ed}^{15}$ that there is a $50 \%$ increased likelihood of survival for those, particularly men, with stronger social relationships. In addition, it has been acknowledged that people in later life may conceal dissatisfaction with conditions that might otherwise be correctable ${ }^{3}$ and that negative life events can be cumulative and can have an increasingly negative impact on quality of life ${ }^{5,16}$ and health status. ${ }^{17}$

A review of the literature over the past 40 years revealed a range of strategies found to positively impact on how older people cope with change and loss. General strategies to minimize the negative impact that these changes might have on quality of life include the individual use of reminiscence, ${ }^{3,18}$ dancing, ${ }^{19,20}$ maintaining activity, ${ }^{21}$ independence, ${ }^{3}$ social relationships and affiliations, ${ }^{22,4,6}$ and engagement with family, ${ }^{23,24}$ mainstream society ${ }^{25}$ and by going out. ${ }^{23}$ When this was not possible, having established primary or secondary (cognitive adaptation), ${ }^{5}$ control and influence over informal care ${ }^{8}$ and/or external help and services ${ }^{3,6,26}$ was seen as an important component in maintaining a good quality of life.

As adapting to change is often a complex and multi-faceted phenomena that is dependent upon a wide range of confounding variables, it is difficult to establish the evidence and support for any one of a range of possible professional and voluntary body interventions. Whilst one author ${ }^{27}$ asserted that there is little evidence to support interventions designed to limit social isolation, one change that people in later life might have to confront, another ${ }^{28}$ maintained that a volunteer befriending scheme proved to be very effective in reducing social isolation, was very positively viewed by the service users and resulted in genuine new friendships being formed, with the volunteer befriender often doing extra, that is, going beyond the formal remit of the scheme. However, a systematic review of health promotion activities aimed at reducing social isolation in later life revealed that whilst group educational and social activities may be effective, the evidence to support the effectiveness of individual home visiting and befriending services remains inconclusive. ${ }^{29}$

A review of the literature was performed in order to broadly explore the subject of adapta-
Correspondence: Francis C. Biley, Room 105 Royal London House, School of Health and Social Care, Bournemouth University, Christchurch Road Bournemouth, UK.

Tel. +44.01202.962214.

E-mail: fbiley@bournemouth.ac.uk

Key words: adaptation, loneliness, social isolation, old age, focus group, action learning.

Funding: this study was funded by a UK Awards for All Lottery grant awarded to Age Concern Dorchester.

Contributions: WH constructed the award application, managed the recruitment of participants, organized the study locations and the final community information event; FB designed the study, managed data collection, storage and analysis, and was the primary author of the final report; JP and MB acted as cohort/process facilitators and subject advisors.

Conflict of interest: the authors declare no conflicts of interests.

Acknowledgments: the project team would like to thank the participants for their enthusiastic responses and time given to this project.

Received for publication: 17 October 2011.

Revision received: 8 December 2011.

Accepted for publication: 12 December 2011.

This work is licensed under a Creative Commons Attribution NonCommercial 3.0 License (CC BYNC 3.0).

CCCopyright F.C. Biley et al., 2012

Licensee PAGEPress, Italy

Nursing Reports 2012; 2:e3

doi:10.4081/nursrep.2012.e3

tion, change and related issues in later life. This revealed that although there was a considerable body of work completed during the 1970s and 80s in Europe and the Americas, ${ }^{15}$ and that the subject is the broad focus of inquiry for a number of recent or ongoing large scale projects in the UK (such as the ESRC Research Program on Extending Quality of Life, and the UK Research Councils' collaborative New Dynamics of Ageing program), there are few contemporary programs or research studies that have specifically explored how those in later life positively adapt to change.

The nature and context of ageing and growing older can be considered to have changed considerably since the 1970 s. $^{25}$ There is now the expectation that good ageing means, among other things, the persistence of social and cultural integration and the successful personal and practical management of an old body. ${ }^{25}$ Given that there are a range of social, financial and health issues that older people may be challenged by, there is a clear need to 
further explore how people in later life deal with these changes in order to maximise the ability to experience good ageing. In addition, a greater understanding of these adaptive needs will enable the health and social care professions and statutory and voluntary bodies to plan assistive services accordingly. With this in mind, the following research questions were formulated.

\section{Research questions}

1. What changes do people experience in later life?

2. How do people cope with those changes?

3 . What would help people cope with those changes?

\section{Materials and Methods}

In order to rigorously and comprehensively explore these questions, a combination of two distinct but related methods across three groups of participants who had experienced loss, change and a need for adaptation in later life was used. Initially, a nominal group method ${ }^{30}$ was used in order to generate ideas and responses to the initial research question. These ideas and responses were then ranked according to the group's perceived priorities. This formed the basis of further discussions that were held during four subsequent meetings of small cooperative learning groups or action learning sets ${ }^{31}$ that used an action learning approach ${ }^{32}$ to link the world of learning to the world of action and sustainability through a reflective process. Finally, the findings from these groups structured the format of a one-day community information event, designed to meet the needs that were expressed through the nominal group and action learning processes.

\section{Procedure}

A series of advertisements and notices were placed in local parish magazines, and village, town and Age Concern publications inviting potential participants from rural and urban situations who have experienced loss and the need to adapt and change as a result of a range of later life events, to attend an initial two hour meeting. At this first meeting, the nature of the research and the program was explained, along with strategies that were used in order to ensure the confidentiality and the anonymity of potential participants. If the potential participants agreed to continue to take part in the group activity they were asked to sign consent forms, and, before the end of the meeting, to complete confidential forms asking for a range of basic demographic details (name, age and contact details). In addition, it was explained how the initial nominal group method of data collection and generation would be employed in order to construct a prioritized list of a number of issues that would form the basis of discussions held at four subsequent action learning set meetings held at weekly intervals with each lasting two hours. Data, in the form of field notes and flip chart summaries of the proceedings were maintained throughout the process. A final sixth meeting, an all day surgery or community information event was held at a central location in order for the findings of the initial meeting and the four subsequent action learning group meetings to be summarized. At this meeting, participants also had the opportunity to meet representatives from a range of invited statutory and non-statutory bodies (such as public transport representatives, the police and home security advisors, benefit advisors, volunteer organisations, occupational therapists, home adaptation specialists and religious bodies) in order to further investigate and suggest solutions to the adaptation issues that had been identified.

\section{Participants}

The project aimed to recruit self-selecting potential participants from a medium-sized market town in southern England, and the immediate surrounding rural areas. At the initial meetings these participants would then join either an urban, sheltered accommodation or rural cohort. As the participants were selfselecting, there was no formal inclusion and exclusion criteria beyond the initial request that participants had had some experience of loss, change and a need to adapt to new situations in later life. There were no specific age restrictions on those who could participate in the study, with the concept of later life being defined by the individuals themselves.

\section{Ethical considerations}

Although the initial potential participants were self-selecting, and participation thereafter voluntary, a number of strategies were put in place to preserve their integrity and wellbeing. Firstly, all the participant/demographic and project data (including field notes and flip chart summaries) were kept in a locked filing cabinet with access only being granted to research team members as required. Pseudonyms were allocated to all participants at the first meeting, and these would be used during data analysis and, where necessary, in final written reports. There was the possibility that emotive subjects could have been raised during the initial and subsequent meetings of the participants. If this resulted in any of the participants becoming upset, then the group facilitator/s, who all have considerable formal and informal counselling experience, would discuss the issue in private with the participant, and if necessary refer them to the confi- dential Age Concern Information and Advice helpline. Following local procedure, a formal project proposal, which included a full Health and Safety risk assessment, progressed through an initial ethical screening process and, following this, was subsequently granted full ethical approval by the Research Committee of Bournemouth University's School of Health and Social Care prior to the commencement of the study.

\section{Results}

Overall, 24 volunteers initially agreed to participate in the project. Eleven participants were recruited to the first meeting of the urban-based cohort, 6 were recruited to the sheltered accommodation-based cohort, and 7 were recruited to the rural-based cohort. In subsequent meetings, cohort size varied, but on average this was 8 (urban), 4 (sheltered accommodation) and 5 (rural). Participants were predominantly female in the urban cohort ( 9 women and 2 men) and the sheltered accommodation cohort (5 women and one man), and exclusively female in the rural cohort. Participant age ranged from 66 to 96 years, with a mean age of 81 years.

Through the use of the nominal focus group method at the three initial meetings, members of all three cohorts identified that they had experienced similar changes in later life, although there were differences in the way that these changes were expressed and, to some extent, prioritized. The urban-based cohort identified these changes as (from most to least priority): losing the ability to easily share aspects of life with another (often following the loss of a life partner) and/or others; a decline in mobility; the experience of bereavement and the need to learn new life skills (that had previously been undertaken by the deceased); changes in health; reduced finances and, finally, the acknowledgement of the need to ask for advice and help. One participant referred to being aware that life shrinks as a result of altered financial status, bereavement, an altered social network and reduced mobility, often in combination. The sheltered accommodation-based cohort prioritized the changes that they had experienced as: a reduction in the ability to socialize (which perhaps emerged as a result of the threat, at that time, of their local day center closing); a reduced physical ability in relation to mobility; the experience of bereavement (with the death of a pet, partner, twin, parent and/or friend); a decline in personal confidence; having to or choosing to move house and location; changes in the home (such as the installation of mobility aids); and having to depend on public transport. Finally, the rural-based cohort identified 
the following changes that they had experienced, presented here again in order of descending priority: the dependence on public transport; reduced levels of confidence; having increasing difficulty in dealing with outside agencies such as utility companies; retirement; physical changes such as a reduction in hearing acuity, sight, and mobility; isolation; and bereavement. Although this study was not designed to make effective and valid comparisons between the three groups, these findings are presented, for interest, in Table 1.

The four subsequent action learning set meetings with each of the three cohorts, (where participants explored this prioritized data in more depth and shared experiences relating to what helped and how they managed to cope with these adaptation needs), generated large amounts of rich data. For example, during the first action learning set meeting of the urban cohort, the participants discussed in more detail their experience of the loss of sharing, which was the issue that they had identified as having highest priority. One participant revealed that, in a relatively short period of time, he had been made redundant and had subsequently lost the use of his company car, and on top of all this his wife, mother-inlaw and then 2 of his pet dogs had died. This prompted the cohort to identify that loss often has multiple consequences (the loss of a job means reduced mobility), that loss of sharing meant emptiness, loneliness, and the need to fill time, especially in the evenings, when you shut your front door and there is nobody to talk to or to eat with. For this cohort, loss of sharing also meant being alone, especially when in crowds (such as having to attend a wedding alone) and having nobody to walk hand-inhand with or to be intimate with, having nobody to bring them a cup of tea in the morning, or to offer them comfort when they are feeling unwell. In the words of one cohort member, loss of sharing meant missing having somebody to discuss nothing with. When asked how members of the cohort managed to cope with all these issues, they replied that it helped to have a reason to get up in the morning and that can be achieved by developing and maintaining activities; by having faith and to have contact with other people. For example, one participant said that her daughter phones each morning to see if I'm up. When asked what could help with the loss of sharing, they identified the significance of facilities and events where they could meet and socialize with others, such as day centers, lunch clubs and a hospice bereavement group. They also identified that participation in this project helped them realize that they were not alone and gave them the opportunity to share their concerns and find solutions to their problems.

These issues were clearly mirrored by the sheltered accommodation and rural cohort

Table 1. Prioritized changes experienced in later life.

\begin{tabular}{|c|c|c|c|}
\hline & & Groups & \\
\hline & Urban & $\begin{array}{c}\text { Sheltered } \\
\text { accommodation }\end{array}$ & Rural \\
\hline Most priority & Loss of sharing & Sociability & Public transport \\
\hline & Mobility & Mobility & Confidence \\
\hline & $\begin{array}{l}\text { Bereavement/need } \\
\text { to learn new skills }\end{array}$ & Bereavement & $\begin{array}{l}\text { Dealing with outside } \\
\text { agencies }\end{array}$ \\
\hline & Physical changes & Confidence & Retiring \\
\hline & Having a shrinking life & $\begin{array}{l}\text { Moving house/location; } \\
\text { changes in the house }\end{array}$ & Physical changes \\
\hline Least priority & Having to ask & Public transport & Isolation \\
\hline
\end{tabular}

who, however, gave them a lower priority than the urban cohort. As a group, the sheltered accommodation cohort was still mourning the loss, over a year previously, of a weekly social group. One participant thought that they had been denied sociability and had deteriorated ever since. Outside facilitators used to run an activity program and a lunch club where everybody seemed to enjoy themselves, it was lovely. The sheltered accommodation cohort still organized some of their own activities and trips, but it wasn't the same.

As the meetings continued, it became clear that although the three cohorts had been able to identify and prioritize specific challenges and needs that require adaptation in later life, it also became clear that many of these issues were very closely related. For example, some of the physical changes that were experienced by some of the participants (such as loss of balance and the need to use walking aids, a fear of falling, arthritis-related reduced mobility and pain, reduced visual acuity) were often related to reduced mobility I can't go to the restaurant because the toilets are up the stairs, which I can't manage and the bus seats are too hard for my arthritis. The result was a tendency to feeling increasingly socially isolated; $I$ yearned to go and see my older sister who had Alzheimer's disease but because of the length of the journey, I couldn't go before she died.

Despite the multitude of problems that the participants expressed in relation to becoming increasingly isolated and lonely, it was often small things that made a difference and helped them overcome these challenges. There was a lady who lived over the road, and we used to wave at each other. I miss her now that she has died, The people in the village always say hello, I never miss our fish and chip lunches and I help out with the coffee mornings and run the raffle; these were typical of the comments that were generated when the participants were asked how they cope with adapting to changes such as moving into a new area.

Although these and further findings were generated in considerably more detail than can be recounted here, it is also important to acknowledge that the research design was such that its prime objective was to encourage participants to explore their own adaptation problems and find their own solutions and methods of coping, as well as to identify what might help them cope in the future. In general, participants were very enthusiastic about having the opportunity to share their experiences of loss, change and adaptation and the strategies that they had employed in order to cope with them. In many instances, these issues were very private and often very emotive but, in the words of one participant, sharing our stories shows that we are not alone, a process that appeared to be beneficial in its own right. This was reinforced by feelings that they were also being proactive - taking charge of the changes that they needed to be involved with. Indeed, participants were often so enthusiastic about this process, that individuals often left the project agenda and prioritized issues behind, and explored issues that were a current priority. However, at other times, the cohort facilitators reported a distinct lack of clarity to the proceedings and cohort processes, with participants coming and going at will, often talking over each other and dominating proceedings, appearing to have no time to listen to others, and having little faith that anything would change. In the words of one participant, Nobody wants to know. It's all been tried before. However, as the meetings progressed, the participants started to work together more, began active listening, information sharing and problem-solving, and expressed enjoyment with having the opportunity to do this. As a result, information was shared and advice given by many participants in relation to both general and more specific topic areas. One person was able, for example, to interpret a newly introduced local bus timetable, another was able to give directions to a nearby town, and give advice related to being hard of hearing, someone else was able to relate her experiences of internet shopping, while another described a telephone conferencing scheme that enabled small groups of individuals to get together on the telephone and talk about their troubles and concerns. The cohorts acknowledged that mere attendance at these sessions 
demonstrated our commitment to adapt and cope with life events and could exist as an example of our own success at coping. Towards the end of the project, one cohort facilitator observed that it was evident that the group have found their own way of supporting, sharing and problem-solving. This continues to be evident as they continue to discuss ideas about fish and chip lunches and hairdressers. We have really learnt a lot from each other was the response from one participant on learning that a representative from the Citizen's Advice Bureau visited the local doctor's surgery once a week. These sessions gave one participant the sense that they weren't alone in having the feelings that they have.

Throughout, the project participants were asked to consider what strategies and services should be in place to help people in later life cope with the changes that they experienced. As the meeting series progressed, solutions to individual's problems were suggested as they arose. In addition to this, more general ideas were generated that the participants felt would help them cope with the changes that take place in later life. It became clear, from the many hours of discussions that took place, that whatever the problem or need for adaptation, the expressed solution was always related to social networking. People needed to talk to each other to explain and exchange information, needed to simply just greet each other in the street, wave from a nearby window, or call on the telephone to talk about the day's events or even to discuss nothing. But as well as this, the participants suggested that there was a potential and significant, perhaps central, role for statutory and non-statutory bodies in the promotion of social networking. They suggested that although they would benefit from having a sense of involvement and ownership of a wide range of group activities, they would also benefit from having a designated and outside organizer to take overall responsibility for organizing activities such as regular telephone conferencing or calling each other on the telephone, running lunch clubs, day centers and programs of (arts and crafts) activities, events and outings, some sort of discussion forum where information can be exchanged (perhaps in combination with lunch clubs and social meetings).

Issues and topics that arose throughout all the initial meetings formed the basis of the program for a final surgery or community information event. Participants from all three cohorts had the opportunity to meet together, to further discuss the issues and they also heard brief presentations from officials from welfare benefits organizations, a housing association, a legal team (who were able to talk about, for example, last wills and testaments, and inheritance tax), and a supplier of telephone-based home safety and communica- tion equipment. Without exception, a final, informal project evaluation received very positive responses, with all participants identifying that they would like to see the project activity continue (through the medium of organized meetings or individual telephone conversations), that they found it useful to learn about the various problems people have or have had, and had got lots of information from the weekly meetings.

\section{Discussion}

Although the project participants clearly identified a wide range of changes that they had experienced that required a variety of adaptation responses, the effectiveness of actual or potential coping strategies seemed to center on their ability to communicate with others and engage in social networking. This activity ranged from simply being able to share experiences with others, to the exchange of advice or information, such as how to get to a nearby town, the time of an up-and-coming coffee morning or at what time to expect buses; to the requirement to find solutions to much complex issues such as the availability of specific financial, housing or legal services. The former social networking activity often appeared to occur spontaneously, through chance meetings in the street, for example. However, there is also a clear need for health and social care professionals and their respective statutory and non-statutory bodies to provide, and carry on providing where the provision already exists, vehicles for informal social networking. Community nurses and other such professionals are clearly in a position to organize coffee mornings, lunch clubs, arts craft and dance ${ }^{19}$ groups and telephone conversations that can provide those with adaptation needs with the opportunity to talk with others and exchange information. Engagement with new media, in the form of training in the use of computers, has been shown to contribute to older adults' well-being and sense of empowerment by affecting their interpersonal interactions, promoting their cognitive functioning and contributing to their experience of control and independence. ${ }^{33}$ However, such a positive response to engagement with the internet and communication technology has not always been found.$^{34}$ There is also a clear need to provide more formal discussion and information exchange meetings, specifically designed to meet specific support and information needs. This would go some way to avoiding the situation where there is a perceived lack of ...information on what was available or who to approach.$^{35}$ It would also seem to suggest that it could have a significant positive impact on quality of life, ${ }^{6,26}$ physical wellbeing ${ }^{7,22}$ and mortality, ${ }^{11}$ and act as an important buffer to the stressors of later life. ${ }^{36}$

These findings and recommendations seem to go some of the way towards ameliorating assertions that there is little evidence to support interventions that might limit social isolation. ${ }^{27,37}$ They support other's assertions that, for example, ...family relationships, social contacts and activities are as valued components of a good quality of life as general health and functional status.$^{23}$ It also supports the concept that group activities with educational or support input, rather than one-to-one interventions, were effective in reducing social isolation and loneliness. ${ }^{29}$ One example of such group activities might include participation in dance circles, where it was found that older people are spontaneously finding their own ways of promoting their own mental and physical well being through music and dance, without being part of a planned health promotion intervention or a music and dance therapy group,$^{20}$ However, there is also a clear need for further research to examine how to provide professional intervention that can reduce...feelings of loneliness..., ${ }^{11}$ for health care policies and public health initiatives ${ }^{15}$ to take these issues into account and, in order to improve health, for social care organizations to facilitate access to social networks. ${ }^{26}$

\section{Conclusions}

It is acknowledged ${ }^{11}$ that there is a pressing urgency to increase the awareness among health professionals that loneliness is a significant and serious risk factor which can negatively impact upon the health and well being of people in later life. This study has endeavoured to uncover some of the challenges that face older people, which, if ignored, may impact on their quality of life. A nominal focus group and action learning set exploration of the changes that those in later life experience, along with their actual and desired methods of coping was performed. A series of weekly meetings with three cohorts of urban, rural and sheltered accommodation participants with an average age of 81 years revealed that they were concerned with having to cope with and adapt to a wide range of experiences. These included the loss of sharing and reduced sociability, reduced mobility, bereavement, physical changes, having to move house and/or location, having to retire, and having to deal with outside agencies. In order to cope with these experiences, participants engaged in a range of activities that centered on aspects of communication and social networking. A coping strategy emerged as participants began to talk to each other and exchange information and advice. When able, they also participated in 
more structured but non-specific social events during which time they had the opportunity to support each other. Participants suggested that there was a role for statutory and nonstatutory bodies and professionals, such as community-based nurses, to provide more formal social networking and information exchange opportunities.

Recommendations for future practice are that statuary and voluntary bodies work collaboratively to plan a range of social meetings in areas commonly frequented by older people in their communities. This study concludes that by empowering older people to meet, exchange information and advice, and to engage in social networking activities, health care professionals such as community-based nurses can help people to adapt to change and loss which in turn positively impacts on the individual's quality of life.

\section{References}

1. Haak M, Dahlin-Ivanoff S, Fänge A, et al. Home as the locus and origin for participation: Experiences among very old Swedish People. Occup Ther J Res 2007;27:95-103.

2. Foster JR. Successful coping, adaptation and resilience in the elderly: an interpretation of epidemiological data. Psychiatr Q 1997;68:189-219.

3. Åberg AC, Sidenvall B, Hepworth M, et al. On loss of activity and independence, adaptation improves life satisfaction in old age - a qualitative study of patients' perceptions. Qual Life Res 2005;14:1111-25.

4. Bond J, Corner L. Quality of Life and Older People. Rethinking Ageing Series. Berkshire: Open University; 2004.

5. Clémence A, Karmaniola A, Green EG, Spini D. Disturbing life events and wellbeing after 80 years of age: a longitudinal comparison of survivors and the deceased over five years. Ageing Soc 2007;27:195213.

6. Gabriel Z, Bowling A. Quality of life from the perspectives of older people. Ageing Soc 2004;24:675-91.

7. Lopez Garcia E, Banegas JR, Granciana Perez-Regadera A, et al. Social network and health-related quality of life in older adults: a population-based study in Spain. Qual Life Res 2005;14:511-20.

8. Thomése F, van Grounou MB. Adaptive strategies after health decline in later life: increasing the person-environment fit by adjusting the social and physical environment. Eur J Ageing 2006;3:169-77.

9. Thuen F, Reime MH, Skrautvoll K. The effect of widowhood on psychological wellbeing and social support in the oldest groups of the elderly. J Ment Health 1997; 6:265-74.

10. Walker A. Understanding Quality of Life in Old Age. Growing Older Series. Berkshire: Open University; 2005.

11. Lecovich E, Jacobs JM, Stessman J. Loneliness, social networks, and mortality: 18 years of follow-up. Int J Aging Hum Dev 2011;72:243263.

12. Sacco VF, Nakhaie MR. Coping with crime: an examination of elderly and nonelderly adaptations. Int J Law Psychiat 2001;24: 305-23.

13. Metz DH. Mobility of older people and their quality of life. Transport Policy 2000;7:14952.

14. Marottoli RA, de Leon CF, Glass TA, et al. Driving cessation and increased depressive symptoms: prospective evidence from the New Haven EPESE. J Am Geriatr Soc 1997;45:202-6.

15. Holt-Lunstad J, Smith TB, Layton JB. Social Relationships and Mortality Risk: A Meta-analytic Review. PLoS Med 2010;7: e1000316.

16. Cheng S-T, Fung HH, CHAN ACM. Living status and psychological well-being: scial comparison as a moderator in later life. Ageing Ment Health 2008;12:654-61.

17. Reblin M, Uchino BN. Social and emotional support and its implication for health. Curr Opin Pyschiat 2008;21:201-5.

18. Cappeliez P, O'Rourke N, Chaudhury H. Functions of reminiscence and mental health in later adulthood. Ageing Ment Health 2005;9:295-301.

19. Paulson $S$. The social benefits of belonging to a 'dance exercise' group for older people. Generat Rev 2005;15:37-41.

20. Paulson S, Willig C. The role of music and emotion in older people's experience of taking part in dance groups. Generations Review 2011;21:1-15.

21. Haak M, Fänge A, Iwarsson S, Ivanoff, SD. Home as a Signification of Independence and Autonomy: Experiences among very old Swedish People. Scand J Occupat Ther 2007;14:16-24.

22. Berkman LF, Glass T, Brissette I, Seeman TE. From social integration to health: Durkheim in the new millennium. Soc Sci Med 2000;51:843-57.

23. Farquhar M. Elderly people's definitions of quality of life. Soc Sci Med 1995;41:143946.

24. Fänge A, Ivanoff SD. The home is the hub of health in very old age: Findings from the ENABLE-AGE Project. Arch Gerontol Geriatr 2009;48;340-5.

25. Tulle-Winton E. Growing old and resistance: towards a new cultural economy of old age? Ageing Soc 1999;19:281-99.

26. McLeod E, Bywaters P, Tanner D, Hirsch M. For the sake of their health: older service users' requirements for social care to facilitate access to social networks following hospital discharge. Br J Soc Work 2008;38: 73-90.

27. Findlay R. Interventions to reduce social isolation among older people: where is the evidence? Ageing Soc 2003;23:647-58.

28. Andrews GJ, Gavin N, Begley S and Brodie D. Assisting friendships, combating loniliness: users' views on a 'befriending' scheme. Ageing Soc 2003;23:349-62.

29. Cattan M, White M, Bond J, Learmouth A. Preventing social isolation and loneliness among older people: a systematic review of health promotion interventions. Ageing Soc 2005;25:41-67.

30. Van de Ven AH, Delbecq AL. The nominal group as a research instrument for exploring health studies. J Am Public Health Assoc 1972;62:337-42.

31. McGill I, Beaty L. Action Learning - a guide for professional, management and education development, 2nd ed. London: Kogan; 1995.

32. Board M, Symons M. Community matron role development through action learning. Primary Health Care 2007;17:19-22.

33. Shapira N, Barak A, Gal I. Promoting older adults' well-being through Internet training and use. Aging Ment Health 2007;11: 477-84.

34. Mellor D, Firth L, Moore K. Can the internet improve the well-being of the elderly? Ageing Int 2008;32:25-42.

35. Walters K, Iliffe S, Orrell M. An exploration of help-seeking behaviour in older people with unmet needs. Fam Pract 2001;18:27782.

36. Blazer DG. Depression and social support in later life: a clear but not obvious relationship. Ageing Ment Health 2007;9:4979.

37. Dreenan V, Walters K, Lenihan P, et al. Priorities in identifying unmet need in older people attending general practice: a nominal group technique study. Fam Pract 2007;24:454-60. 